\title{
VALIDATION OF THE SCALE OF PERCEIVED SELF-EFFICACY OF MATERNAL PARENTING IN BRAZILIAN SAMPLE
}

\author{
Rosana Maria Tristão, ${ }^{1,2}$, Elaine Rabelo Neiva², Christopher R Barnes ${ }^{3}$, \\ Elvidina Adamson-Macedo ${ }^{4}$
}

\begin{abstract}
Introduction: self-efficacy matches the belief that a person has that she is able to produce the results she wants to achieve. The beliefs of self-efficacy that parents have about the baby emerge as a powerful predictor of positive parenting. Objective: this study aimed to evaluate the maternal self-efficacy behavior in hospitalized mothers and validate an instrument for measuring this concept developed and validated in England by Barnes and Adamson-Macedo, in 2007. Method: this crosssectional exploratory study convenience cohort comprised 87 mothers of newborn babies, 26 premature and 61 full-term infants. The scale Perceived Maternal Parenting Self-Efficacy (PMP S-E), which consists of 20 items that represent four subscales was tested for reliability and validity. Results: the internal consistency of the scale PAEPM reached a value of .86, the internal consistency and reliability estimates for each of the subscales also reached acceptable values. Exploratory Factor Analysis (EFA) confirmed the validity of the construct and the scores of self-efficacy were normally distributed for both subgroups and total sample. Conclusions: PMP S-E scale proved to be an easy application tool and psychometrically robust, reliable and valid for use with mothers of hospitalized new-borns both premature as the term clinically stable. It is a reliable method of identifying mothers of babies who need more support from the hospital staff.
\end{abstract}

Keywords: self-efficacy, neonatal care, parenting, validation, health psychology.

\section{INTRODUCTION}

Self-efficacy matches the belief that a person has that she is able to produce the results she wants to achieve. The beliefs of self-efficacy that parents have about the baby emerge as a powerful predictor of positive parenting. The concept of self-efficacy emerged between the years 1940 and 1980 and corresponds to the belief that a person can successfully achieve the desired outcome ${ }^{1-4}$. This concept points out that the development of these beliefs begins in the individual from the first weeks after birth.

Thus, the experiences that a person has, whether success or failure, can influence the development of her/his sense of self-efficacy. The beliefs of self-efficacy that parents have about their newborn baby emerge as a powerful predictor of positive parenting practices. For example, the trust that parents have that they will be good parents can be a predictor of how it will be the care they will have with their baby ${ }^{5,6}$.

Symptoms of mental disorders, mood, personal counseling, and family support are factors that influence the concept of self-efficacy of parents. In addition to these factors others such as the support of external social group family, the child's temperament, history of psychiatric illness and postpartum sadness may also influence the concept of parental self-efficacy. As an example, the occurrence of postpartum depression that may be associated with low perception of maternal selfefficacy may also influence negatively the construction of the mother-baby bond and consequently the development of the child. Babies of depressed mothers may have less vocalization, less spontaneity, less interaction with others, show more negative expressions, high levels of cortisol

\footnotetext{
1 Visiting Researcher at University of Oxford John Radcliffe Hospital Oxford, UK, OX3 9DU

2 Universidade de Brasília, Brasília, Campus Darcy Ribeiro, Brasil, 70910-900

3 University of Derby, Kedleston Road Campus, UK, DE22 1GB

4 University of Wolverhampton (Retired), West Midlands, Inglaterra

* Bolsista CNPq - Brasil

Corresponding author:
} 
and avoid eye contact. As for other psychiatric disorders during the postpartum, maternal depression is also associated with increased risk of manifestation of aggressive behavior, including suicide attempts and infanticide. It is noteworthy that the change in the baby's development is directly linked to the type of depression that the mother is suffering $^{7-9}$. Depression can be transient and/or prolonged, and the transient depression can be of no significant influence on child development. In addition, the depressed mother may develop interaction with your child in two distinct ways: intrusive or withdrawn. In the first case the superstimulating mother negatively interferes in the activities developed by the baby. In the second case the mother is away from the child emotionally and rarely speaks to the infant ${ }^{10,11}$.

It is also known that psychosocial factors such as the number of pregnancies, number of births, number of living children, relationship time, low level of education, low socioeconomic status, unplanned pregnancy, premature birth, trying to terminate a pregnancy, negative feelings regarding the child, preference for baby's sex also exert great influence on the mother-infant relationship and may have implications on the perception of self-efficacy of maternal parenting $7,10,11$.

Barnes and Adamson-Macedo ${ }^{12}$ developed a questionnaire to measure the perception of maternal self-efficacy, the scale Perceived Maternal Parenting Self-Efficacy (PMPS-E) which aims to assess the mother's perceptions about their ability to understand and care for your newborns admitted to the intensive care unit environment. It was conceived by the need to create a new mechanism to evaluate the maternal self-efficacy and stemmed from the limitations of existing questionnaires. The original instrument was designed to evaluate the concept of self-efficacy in mothers of premature babies, one of the risk factors among the aforementioned predisposing to feelings of low perception of maternal self-efficacy.

The overall objective is to validate the questionnaire drawn up by Barnes and AdamsonMacedo ${ }^{12}$ in Brazil replicating the original study and validation of the expanding population of term infants. Adding to this main objective we seek to also answer a question that underlies this work which is to investigate whether the baby's prematurity is a factor that interferes with the concept of perceived self-efficacy of maternal parenting thereby indicating a relationship with minor belief and perception of self-efficacy.

\section{METHODS}

This is a cross-sectional exploratory study convenience cohort. One hundred seventy (170) mothers of babies admitted to rooming system and mothers of babies admitted to the intensive care unit of a Brazilian tertiary care hospital were invited to participate of this study. Mothers were invited to participate between January 2013 and April 2014 at the University Hospital of Brasilia. The study included mothers whose babies were born at term and preterm infants who were in stable health condition. Infants were excluded with genetic malformations or neurologic disorders. The number of mothers is based upon the number of participants in the original study sample of Barnes and AdamsonMacedo.

All instruments application procedure was expected to last for around 20 minutes respecting the clinical condition of the mother and her physical and emotional willingness to answer the question. It is noteworthy that the application of these instruments was interrupted at any time the mother indicated physical ailments and / or desire to stop the activity. Before the interview begins the mother was informed about the research objectives and was invited to sign the Informed Consent (IC). The Research Ethics Committee of the University of Brasilia approved the study.

Clinical data of the mother and baby were collected from the maternity records and variables such as baby gender; gestational age and the baby's age in days; APGAR scores of 1 and 5 minutes; type of delivery; occurrence and type of fetal distress; occurrence of complications in childbirth; number of painful procedures experienced by the baby; smoking; number of consultations during the prenatal period; number of previous pregnancies, abortions and deceased child. The sociodemographic questionnaire investigated maternal age, maternal education level, marital status, region of residence and declared color.

The perception of self-efficacy of maternal parenting was measured with the version translated into Brazilian Portuguese of Perceived Maternal Parenting Self-Efficacy (PMP SE) which received the title of Percepção de Autoeficácia de Parentalidade Materna (PAEPM). The version used the PAEPM scale was translated into Portuguese by the authors of the original study and reviewed by other authors of this article. The version in use of PAEPM tool was composed of 20 items (final score ranging from 2080 ) with four subscales or factors theoretically designed: Factor 1 Taking Care; Factor 2 Eliciting Behavior; Factor 3 Reading Behavior; and Factor 4 Situational Beliefs. The scale was applied between one and 28 days in the neonatal period and had a time of application provided for around 10 minutes.

The PAEPM scale was translated into direct and reverse way and resulted in the following items in Brazilian Portuguese: 1. I believe I can tell when my baby is tired and needs to sleep; 2 . I believe that I have control over my baby; 3 . I can tell when my baby is sick; 4 . I can read my baby's cues; 5 . I can make my baby happy; 6 . I believe that my baby responds well to me; 7 . I believe that my baby and I have a good interaction with each other; 8 . I can calm my baby when he/she has been crying; 9 . I am good at soothing my baby when he/she becomes upset; 10. I am good at soothing my baby when he/she becomes fussy; 11 . I am good at soothing my baby when he/she continuously cries; 12 . I am good at calming my baby when he/she becomes more restless; 13 . I am good at understanding what my baby wants; 14 . I'm good at getting my babies attention; 15. I am good at knowing what activities my baby does not enjoy; 16 . I am good in keeping 
my baby occupied. 17. I am good at feeding my baby; 18. I am good at changing my baby; 19 . I am good at bathing my baby; 20. I can show affection to my baby. In accordance with the original scale items were allocated exclusively to each factor according to the theoretical relevance and contextual basis. This grouping allowed the calculation of sub-scores and the total score.

\section{Statistical analysis of the data}

Data analysis was performed using the following statistical features: independent sample t-test, the Cronbach's alpha, Pearson correlation, one-way ANOVA and two-way ANOVA and factor analysis with principal components analysis performed in Statistical Package for Social Sciences
(SPSS IBM-V.21). Data from mothers of premature babies full term babies respective groups were initially analyzed separately and later as a single sample.

\section{RESULTS}

Among the 170 mothers invited to participate scores of PAEPM scale and socio-demographic were collected, but it was not possible to collect complete data from 83 mothers, especially clinical data due to difficult access to medical records. The final sample consisted of 87 children, 26 preterm infants being 42 male $(47.2 \%)$ and 61 term infants and healthy babies, 18 male (69.2\%). Table 1 shows the demographic and clinical maternal and babies (Table 1 ).

Table 1: Characteristics for premature babies and full-term groups and the overall sample expressed as mean, standard deviation (SD), minimum and maximum values for continuous variables, number of cases and percentages for variables categorical.

\begin{tabular}{|c|c|c|c|c|c|c|c|c|c|c|c|c|}
\hline \multirow[t]{3}{*}{ Characteristics } & \multicolumn{12}{|c|}{ Groups } \\
\hline & \multicolumn{4}{|c|}{ Full Term $(\mathrm{N}=61)$} & \multicolumn{4}{|c|}{ Premature $(\mathrm{N}=26)$} & \multicolumn{4}{|c|}{ Total $(\mathrm{N}=87)$} \\
\hline & M & DP & Min & $\operatorname{Max}$ & M & DP & Min & Max & M & DP & Min & Max \\
\hline Baby birth weight (grams) & 3234.4 & 530.7 & 2480 & 4365 & 1611.4 & 517.3 & 700 & 2850 & 2551.1 & 961.5 & 700 & 4365 \\
\hline Gestational age (weeks) & 38.8 & 1.2 & 37 & 41 & 32.6 & 1.9 & 30 & 36 & 36.5 & 3.4 & 30 & 41 \\
\hline Age in days & 3.2 & 1.3 & 2 & 7 & 10.3 & 6.3 & 2 & 23 & 5.2 & 4.7 & 2 & 23 \\
\hline \multicolumn{13}{|l|}{ Gender $(\mathrm{N}, \%)$} \\
\hline Male & 24 & 40.7 & & 18 & 69.2 & & & 42 & 49.4 & & & \\
\hline Female & 35 & 59.3 & & 8 & 30.8 & & & 43 & 50.6 & & & \\
\hline \multicolumn{13}{|l|}{ Fetal distress $(\mathrm{N}, \%)$} \\
\hline acute & 4 & 6.8 & & & 5 & 21.7 & & & 9 & 11 & & \\
\hline chronic & 0 & 0 & & & 8 & 34.8 & & & 8 & 9.8 & & \\
\hline $1 \mathrm{~min}$ Apgar & 8.1 & 1.3 & 4 & 10 & 6.8 & 1.8 & 1 & 9 & 7.6 & 1.6 & 1 & 10 \\
\hline 5th min Apgar & 9.2 & .6 & 7 & 10 & 8.4 & .8 & 6 & 10 & 8.9 & .8 & 6 & 10 \\
\hline Number of painful procedures & 3.5 & .7 & 3 & 5 & 34.5 & 22.3 & 6 & 86 & 19.6 & 22.3 & 3 & 86 \\
\hline Maternal age & 28.4 & 6.7 & 16 & 43 & 25.8 & 5.7 & 16 & 36 & 27.6 & 6.5 & 16 & 43 \\
\hline Number of prenatal visits & 8.7 & 2.8 & 4 & 18 & 5.7 & 2.2 & 1 & 9 & 7.7 & 2.9 & 1 & 18 \\
\hline Deceased children & .1 & .3 & 0 & 1 & .1 & .2 & 0 & 1 & .1 & .2 & 0 & 1 \\
\hline Previous pregnancies & 1.9 & 1.8 & 0 & 12 & .9 & 1.4 & 0 & 5 & 1.6 & 1.8 & 0 & 12 \\
\hline Previous abortions & .2 & .5 & 0 & 2 & .1 & .2 & 0 & 1 & .2 & .4 & 0 & 2 \\
\hline \multicolumn{13}{|l|}{ Type of delivery $(\mathrm{N}, \%)$} \\
\hline Abdominal & 27 & 44.3 & & & 19 & 73.1 & & & 46 & 52.9 & & \\
\hline Vaginal & 34 & 55.7 & & & 7 & 26.9 & & & 41 & 47.1 & & \\
\hline \multicolumn{13}{|l|}{ Childbirth complications ( $\mathrm{N}, \%)$} \\
\hline Yes & 15 & 24.6 & & & 12 & 46.2 & & & 27 & 31.0 & & \\
\hline Smoking $(\mathrm{N}, \%)$ & 6 & 9.8 & & & 1 & 3.8 & & & 7 & 8.1 & & \\
\hline \multicolumn{13}{|l|}{ Marital status $(\mathrm{N}, \%)$} \\
\hline Single & 20 & 32.8 & & & 8 & 30.8 & & & 28 & 32,2 & & \\
\hline Stable union & 22 & 36.1 & & & 7 & 26.9 & & & 29 & 33.3 & & \\
\hline Separate & 1 & 1.6 & & & 0 & 0.0 & & & 1 & 1.1 & & \\
\hline Married & 18 & 29.5 & & & 11 & 42.3 & & & 28 & 33.3 & & \\
\hline \multicolumn{13}{|l|}{ Maternal education $(\mathrm{N}, \%)$} \\
\hline 1-4 series & 3 & 4.9 & & & 1 & 3.8 & & & 4 & 4.6 & & \\
\hline $5-8$ series & 11 & 18.0 & & & 3 & 11.5 & & & 14 & 18.1 & & \\
\hline Incomplete High School & 11 & 18.0 & & & 4 & 15.4 & & & 15 & 17.2 & & \\
\hline Complete High School & 26 & 42.6 & & & 11 & 42.3 & & & 37 & 42.5 & & \\
\hline Incomplete College & 5 & 8.2 & & & 1 & 3.8 & & & 6 & 6.9 & & \\
\hline Graduated & 4 & 6.6 & & & 6 & 23.1 & & & 10 & 11.5 & & \\
\hline Postgraduate & 1 & 1.6 & & & 0 & 0.0 & & & 1 & 1.1 & & \\
\hline
\end{tabular}


To analyze PAEPM results the items were grouped within the four factors proposed by the original study and the sub-scores for each factor; the overall score was calculated for both groups and for the sample as a whole. Overall, there was great variability in the total score of the scale with values ranging from 34-80 points. The overall results for the scale factors with their respective values are shown in separate items in Table 2 for each group and for the whole sample.

Table 2: Mean values, standard deviation, t-test (degree of freedom) for independent samples and compared between groups with p-value, confidence interval (95\%) of scores of Maternal Self-Efficacy Scale, total factor and the scale items for premature babies and full-term groups

\begin{tabular}{|c|c|c|c|c|c|c|c|c|c|c|c|c|c|c|c|c|c|}
\hline \multirow[t]{2}{*}{$\begin{array}{l}\text { Factors } \\
\text { and Item }\end{array}$} & \multicolumn{3}{|c|}{$\begin{array}{l}\text { Premature } \\
\mathrm{N}=26\end{array}$} & \multicolumn{2}{|c|}{ IC 95\% } & \multicolumn{3}{|c|}{$\begin{array}{l}\text { Full-Term } \\
\mathrm{N}=61\end{array}$} & \multicolumn{2}{|c|}{ IC 95\% } & \multicolumn{3}{|c|}{$\begin{array}{l}\text { Total } \\
\mathrm{N}=\mathbf{8 7}\end{array}$} & \multicolumn{2}{|c|}{ IC 95\% } & \multicolumn{2}{|c|}{$\begin{array}{c}\text { Test compared } \\
\text { samples }\end{array}$} \\
\hline & M & SD & $\begin{array}{c}t \\
(25)\end{array}$ & $\mathbf{L}$ & U & M & SD & $\begin{array}{c}t \\
(60)\end{array}$ & $\mathbf{L}$ & $\mathbf{U}$ & $M$ & SD & $\begin{array}{c}t \\
(86)\end{array}$ & $\mathbf{L}$ & U & $\begin{array}{c}\mathrm{t} \\
(85)\end{array}$ & $p$ \\
\hline TC & 13.2 & 2.3 & 22.2 & 20.6 & 24.8 & 13.2 & 1.9 & 52.6 & 12.7 & 13.7 & 13.2 & 2.0 & 60.0 & 12.7 & 13.6 & 157 & .876 \\
\hline EC & 22.7 & 5.1 & 34.5 & 10.2 & 11.5 & 22.4 & 3.7 & 46.6 & 21.5 & 23.4 & 22.5 & 4.1 & 50.7 & 21.6 & 23.4 & -.222 & .825 \\
\hline EB & 18.2 & 4.2 & 26.9 & 60.0 & 70.0 & 18.9 & 2.9 & 50.7 & 18.1 & 19.6 & 18.6 & 3.3 & 52.5 & 17.9 & 19.4 & .913 & .364 \\
\hline RB & 10.9 & 1.5 & 21.5 & 16.4 & 19.9 & 10.9 & 1.3 & 63.1 & 10.5 & 11.2 & 10.9 & 1.4 & 72.3 & 10.6 & 11.2 & .150 & .881 \\
\hline TS & 65.0 & 12.9 & 28.3 & 12.2 & 14.1 & 65.5 & 8.2 & 62.1 & 63.4 & 67.6 & 65.3 & 9.3 & 64.8 & 63.3 & 67.3 & 279 & .781 \\
\hline 1 & 2.8 & .6 & 24.0 & 2.6 & 3.1 & 3.1 & .7 & 33.8 & 2.9 & 3.3 & 3.1 & .7 & 41.1 & 2.9 & 3.2 & 1.630 & .107 \\
\hline 2 & 3.1 & .9 & 16.8 & 2.7 & 3.5 & 3.4 & .6 & 38.6 & 3.2 & 3.6 & 3.3 & .8 & 40.2 & 3.1 & 3.5 & 1.827 & .071 \\
\hline 3 & 2.9 & .8 & 17.6 & 2.6 & 3.3 & 3.0 & .7 & 29.7 & 2.8 & 3.2 & 3.0 & .8 & 35.1 & 2.8 & 3.1 & .379 & .706 \\
\hline 4 & 3.0 & .8 & 17.8 & 2.7 & 3.4 & 3.2 & .7 & 34.7 & 2.9 & 3.3 & 3.1 & .7 & 39.0 & 2.9 & 3.3 & .493 & .623 \\
\hline 5 & 3.7 & .4 & 43.1 & 3.5 & 3.9 & 3.7 & .5 & 55.8 & 3.5 & 3.8 & 3.7 & .5 & 70.6 & 3.6 & 3.8 & -.413 & .681 \\
\hline 6 & 3.5 & .8 & 21.3 & 3.1 & 3.8 & 3.5 & .5 & 47.2 & 3.4 & 3.7 & 3. & .7 & 50.1 & 3.4 & 3.6 & .475 & .636 \\
\hline 7 & 3.7 & .5 & 35.9 & 3.5 & 3.9 & 3.6 & .5 & 51.8 & 3.5 & 3.7 & 3.7 & .5 & 63.0 & 3.5 & 3.7 & -.717 & .475 \\
\hline 8 & 3.3 & .8 & 19.5 & 3.0 & 3.7 & 3.3 & .7 & 36.0 & 3.1 & 3.4 & 3.3 & .7 & 41.0 & 3.1 & 3.4 & -.383 & .703 \\
\hline 9 & 3.1 & .8 & 17.7 & 2.7 & 3.4 & 3.1 & .6 & 34.8 & 2.9 & 3.2 & 3.1 & .7 & 38.9 & 2.9 & 3.2 & -.191 & .849 \\
\hline 10 & 3.2 & .8 & 19.5 & 2.9 & 3.5 & 3.1 & .7 & 32.6 & 2.9 & 3.3 & 3.2 & .8 & 38.5 & 3.0 & 3.3 & -.368 & .713 \\
\hline 11 & 2.9 & .9 & 16.6 & 2.5 & 3.3 & 3.0 & .8 & 29.5 & 2.8 & 3.2 & 3.0 & .8 & 34.3 & 2.8 & 3.2 & .454 & .651 \\
\hline 12 & 2.9 & .9 & 16.6 & 2.5 & 3.3 & 3.0 & .7 & 32.4 & 2.8 & 3.2 & 3.0 & .8 & 36.4 & 2.8 & 3.1 & .393 & .695 \\
\hline 13 & 3.1 & .8 & 18.7 & 2.7 & 3.4 & 3.1 & .6 & 37.2 & 2.9 & 3.3 & 3.1 & .7 & 41.5 & 3.0 & 3.3 & .291 & .771 \\
\hline 14 & 3.3 & .9 & 17.5 & 2.9 & 3.7 & 3.1 & .6 & 37.5 & 2.9 & 3.3 & 3.2 & .7 & 40.0 & 3.0 & 3.3 & -.918 & .361 \\
\hline 15 & 3.0 & .9 & 16.2 & 2.6 & 3.4 & 2.9 & .7 & 32.1 & 2.7 & 3.1 & 2.9 & .8 & 35.7 & 2.8 & 3.1 & -.479 & .633 \\
\hline 16 & 2.9 & .7 & 18.7 & 2.6 & 3.2 & 2.8 & .7 & 28.0 & 2.6 & 3.0 & 2.9 & .8 & 34.2 & 2.7 & 3.0 & -.775 & .441 \\
\hline 17 & 3.4 & .5 & 29.4 & 3.2 & 3.6 & 3.5 & .5 & 51.3 & 3.0 & 3.6 & 3.5 & .5 & 59.5 & 3.38 & 3.6 & .790 & .431 \\
\hline 18 & 3.5 & .8 & 20.4 & 3.2 & 3.9 & 3.5 & .5 & 49.7 & 3.4 & 3.7 & 3.6 & .6 & 50.3 & 3.42 & 3.7 & .227 & .821 \\
\hline 19 & 3.2 & .8 & 18.4 & 2.8 & 3.6 & 3.3 & .7 & 32.9 & 3.1 & 3.5 & 3.3 & .8 & 38.0 & 3.12 & 3.4 & .426 & .671 \\
\hline 20 & 3.6 & .5 & 32.0 & 3.4 & 3.8 & 3.7 & .5 & 55.8 & 3.5 & 3.8 & 3.7 & .5 & 65.0 & 3.59 & 3.8 & .540 & .590 \\
\hline
\end{tabular}

Note: $\mathrm{M}=$ mean; $\mathrm{SD}=$ standard deviation- $; \mathrm{L}=$ lower; $\mathrm{U}=$ upper; $\mathrm{TC}=$ Factor 1 Taking Care; EB = Factor 2 Eliciting Behavior; $\mathrm{RB}=$ Factor 3 Reading Behavior; $\mathrm{SB}=$ Factor 4 Situational Beliefs; and TS = Total Score of scale. The significance value for t-test for independent sample was $p=.000$ for all sample groups and all factors and analysis items.

The overall average of self-efficacy score was around $65(\mathrm{SD}=9)$ and the median around 66 . The distribution of scores for each subgroup is demonstrated in Figure 1 . The degrees of spread of the scores seem to suggest that PAEPM tool has a reasonable degree of discrimination, although a slight downward slope (skeweness $=-.80$ ). The asymmetry is not significant at the $5 \%$ level, indicating that the scores of self-efficacy are normally distributed for both subgroups and total sample). The premature and full-term groups were compared by Friedman's t-test to see if the results differed and there was no statistically significant difference for any of the factors or scale items (Table 2 ). The sample passed the test Levine for homogeneity (Figure 1).
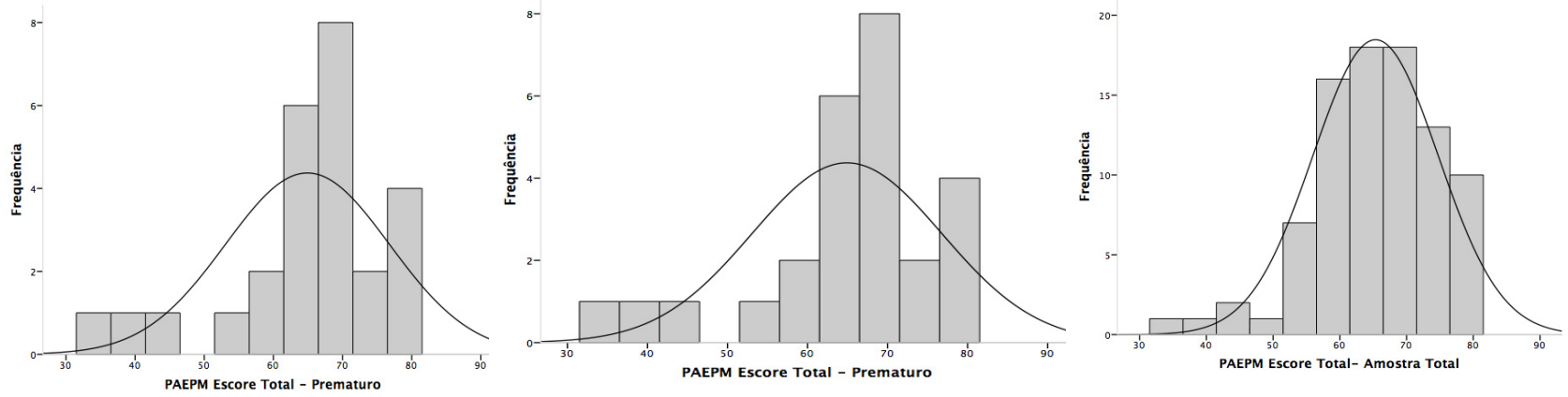

Figure 1: Distribution of parenting perception scores and maternal self-efficacy for preterm (left) and term infants (center) and total sample (right) 


\section{Reliability}

Internal consistency and reliability $(\mathbf{N}=\mathbf{8 7})$

Cronbach's alpha coefficient was used to calculate the internal consistency estimates for the total sample of PAEPM scale and reached the .86 value exceeding the suggested reference value for new ranges of $0.7^{13,14}$. The internal consistency and reliability estimates for each of the subscales also reached acceptable values: Taking Care subscale (.78) Eliciting Behaviors subscale (.74), sub-scale Reading Behavior (.70) and Situational Beliefs subscale (.80). The intra-class correlation to the average of the measurements was $r=.81$ $(p=.000)$. The Pearson bivariate correlation analysis for all items compared to the total score of the scale showed highly significant correlation $(p=.006)$ for all items ranging from $r=.53$ (ability to feed the baby) and $r=.92$ (ability to calm the impatient baby).

\section{Validity \\ Construct validity}

The PAEPM tool (Perceived Self-efficacy of Maternal Parenting) was evaluated for construct validity through the Exploratory Factor Analysis (EFA). In the first instance an AFE was held on the results of all 87 participants using principal component analysis, in combination with a varimax rotation; this yielded four factors with Eigen values greater than one. Factor 1 had an Eigen value of 8.90 and explained $44.5 \%$ of the variance, Factor 2 had an Eigen value of 1.94 and explained $9.75 \%$ of the variance, Factor 3 had an Eigen value of 1:58 and explained $7.9 \%$ of variance and Factor 4 had an Eigen value of 1:37 explaining $6.8 \%$ of the variance (Table 3 ). Following this initial assessment, the items with Eigen value above .1 were attributed to factors depending on the overall magnitude of the product to be loaded on one factor against the other and conceptual adjustment item in the factor / subscale best fits (Table 4). Only item 20 (I know how to show affection for my baby) did not fit the above criteria (Table 3 and 4).

The emergence of these four different factors was congruent with the four subscales corresponding proposals in the original article and had been grounded in the theory of self-efficacy, the literature review on relevant scales and expertise of the authors of the original article ${ }^{12}$. The sampling adequacy based on the Kaiser-MeyerOlkin ( $\mathrm{KMO}=.864$ ) was adopted and the data suitable for the reduction with Bartlett's test sphericity $\left(X^{2}=1,183.2, p=.000\right)$ (Figure 2$)$.

The distribution of components based on the matrix of the rotated components of the factors has the composition possibilities according to the distribution of the items (Table 5). These possibilities include the distribution structure of the items for each original study factor except for items 5 "I can make my baby happy", originally allocated in Factor 2 Eliciting Behavior and, according to this analysis, correlated with items of Factor 1 Taking Care or Factor 4 Situational Beliefs; and item 16 I am good in keeping my baby occupied, originally allocated to the Factor 1 Taking Care, which correlated with items Factor 3 Reading Behavior and Factor 4 Situational Beliefs (Table 5).

\section{Interaction between clinical and sociodemo- graphic variables and factors and components}

Data were analyzed to see if the clinical and demographic variables had any effect on the responses of mothers to PAEPM scale. One-way ANOVA was used for each independent variable on the items of the total sample and two-way ANOVA with the variable as a factor group. The independent variables in the One-Way ANOVA and dependent variables in the Two-Way ANOVA were gestational age, maternal age, number of consultations in prenatal, baby gender, baby age in days, Apgar 1 and 5 minutes, type birth, occurrence and type of fetal distress, complications in childbirth, smoking,

Table 3: Total variation explained to the components of PAEPM scale

\begin{tabular}{|c|c|c|c|c|c|c|}
\hline \multirow[t]{2}{*}{ Component } & \multicolumn{3}{|c|}{ Eigen value } & \multicolumn{3}{|c|}{ Sums of rotations of Square Loads } \\
\hline & Total & $\%$ Variance & $\%$ Cumulative & Total & \% Variance & $\%$ Cumulative \\
\hline 1 & 8.901 & 44.505 & 44.505 & 5.073 & 25.363 & 25.363 \\
\hline 2 & 1.949 & 9.746 & 54.251 & 3.115 & 15.577 & 40.940 \\
\hline 3 & 1.579 & 7.897 & 62.148 & 3.100 & 15.500 & 56.441 \\
\hline 4 & 1.369 & 6.847 & 68.995 & 2.511 & 12.555 & 68.995 \\
\hline 5 & .941 & 4.706 & 73.701 & & & \\
\hline 6 & .717 & 3.585 & 77.286 & & & \\
\hline 7 & .613 & 3.067 & 80.353 & & & \\
\hline 8 & .587 & 2.936 & 83.290 & & & \\
\hline 9 & .518 & 2.589 & 85.879 & & & \\
\hline 10 & .504 & 2.519 & 88.398 & & & \\
\hline 11 & .429 & 2.144 & 90.542 & & & \\
\hline 12 & .386 & 1.932 & 92.473 & & & \\
\hline 13 & .331 & 1.654 & 94.127 & & & \\
\hline 14 & .273 & 1.364 & 95.492 & & & \\
\hline 15 & .232 & 1.162 & 96.654 & & & \\
\hline 16 & .190 & .952 & 97.606 & & & \\
\hline 17 & .153 & .764 & 98.370 & & & \\
\hline 18 & .129 & .645 & 99.015 & & & \\
\hline 19 & .122 & .608 & 99.624 & & & \\
\hline 20 & .075 & .376 & 100.000 & & & \\
\hline
\end{tabular}


Table 4: PMP SE, subscales, items and loads of factor analysis. The t-test was used to compare the two groups of the sample

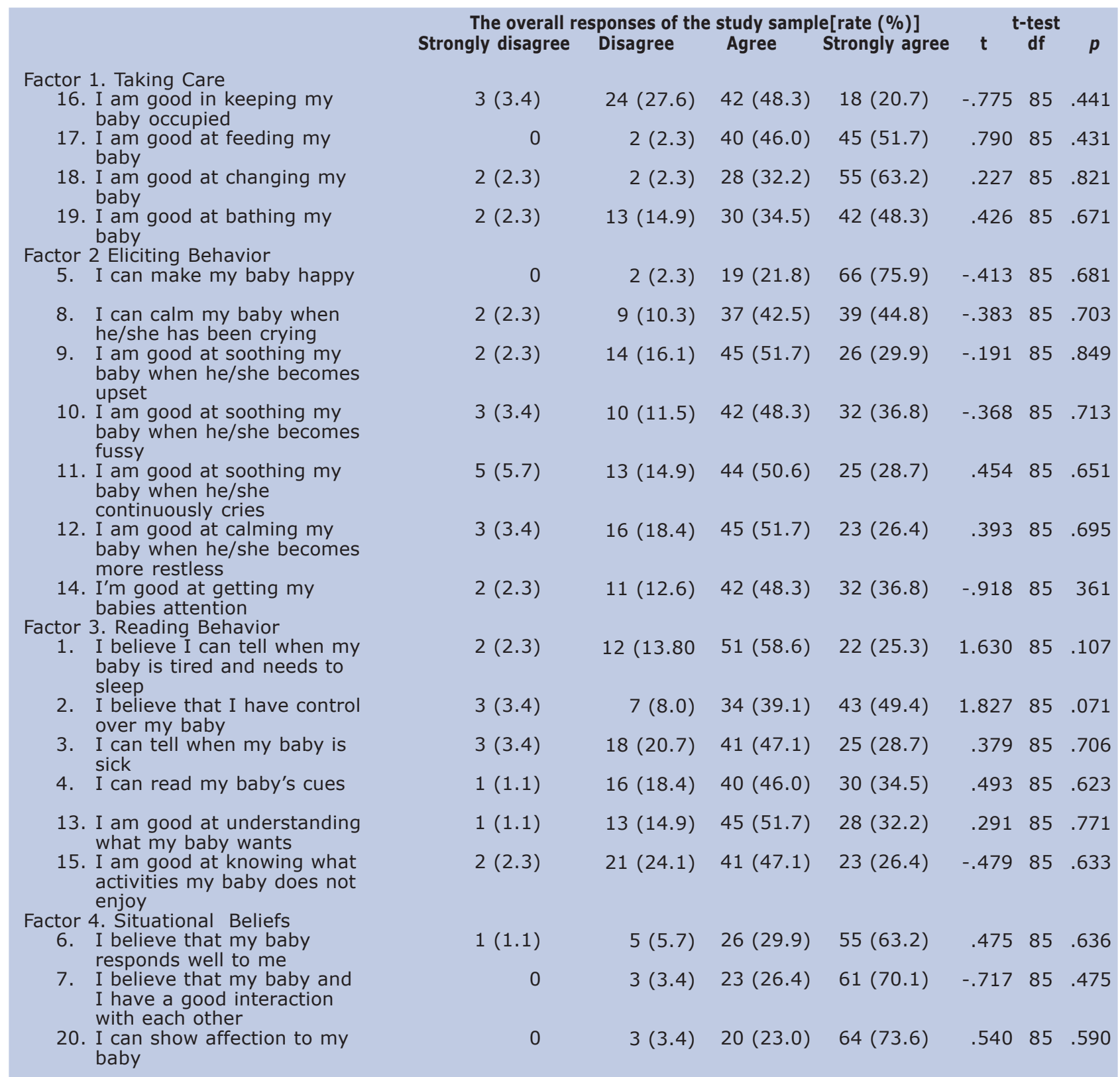

The emergence of these four different factors was congruent with the four subscales corresponding proposals in the original article and had been grounded in the theory of self-efficacy, the literature review on relevant scales and expertise of the authors of the original article ${ }^{12}$. The sampling adequacy based on the Kaiser-Meyer-Olkin (KMO = $.864)$ was adopted and the data suitable for the reduction with Bartlett's test sphericity $\left(X^{2}=\mathbf{1}, \mathbf{1 8 3 . 2}, p=.000\right)$.

Scree Plot

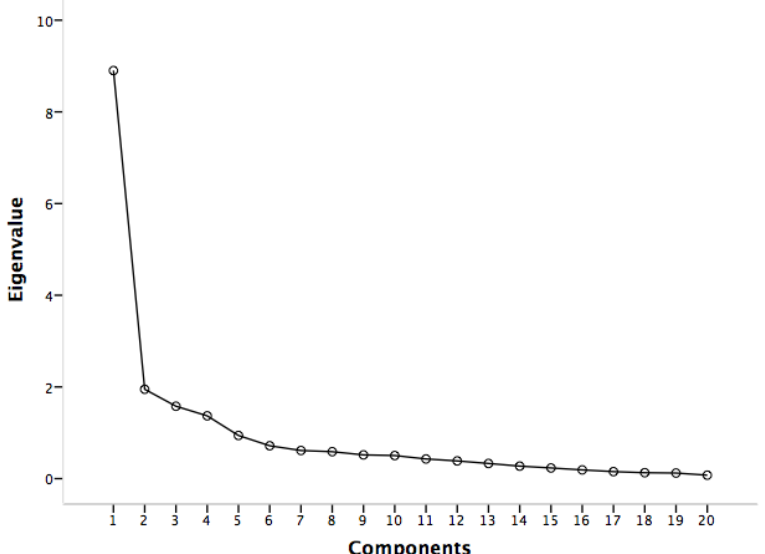

Component Plot in Rotated Space

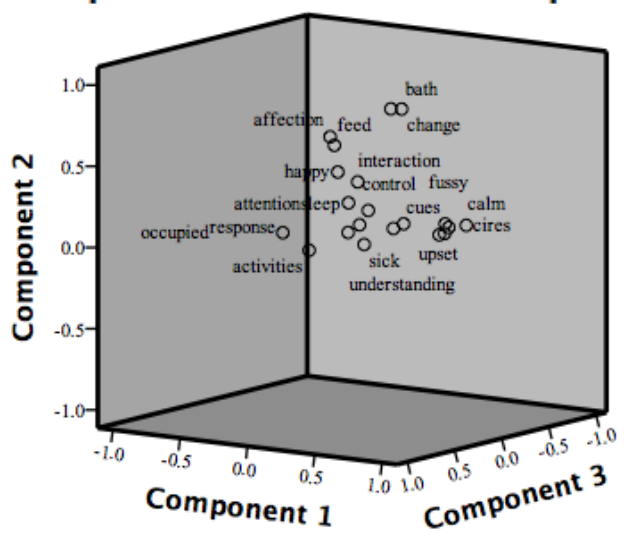

Distribution of Eigen values associated to the components in scree plot (right) and spatial representation of the items depending on the components (left) where the items are represented by their key words 
Table 5: Matrix of rotated components

\begin{tabular}{|c|c|c|c|c|}
\hline & \multicolumn{4}{|c|}{ Components } \\
\hline & 1 & & & 4 \\
\hline 1. I believe I can tell when my baby is tired and needs to sleep; & & & & .745 \\
\hline 2. I believe that I have control over my baby; & .351 & & .378 & .509 \\
\hline 3. I can tell when my baby is sick; & .313 & & .341 & .744 \\
\hline 4. I can read my baby's cues; & .470 & & & .642 \\
\hline 5. I can make my baby happy; & & .578 & .497 & \\
\hline 6. I believe that my baby responds well to me; & .415 & & .570 & \\
\hline 7. I believe that my baby and I have a good interaction with each other: & .362 & .484 & .554 & \\
\hline 8. I can calm my baby when he/she has been crying; & .831 & & & \\
\hline 9. I am good at soothing my baby when he/she becomes upset; & .790 & & & \\
\hline 10. I am good at soothing my baby when he/she becomes fussy; & .860 & & & \\
\hline 11. I am good at soothing my baby when he/she continuously cries; & .866 & & & \\
\hline 12. I am good at calming my baby when he/she becomes more restless; & .844 & & & \\
\hline 13. I am good at understanding what my baby wants; & .571 & & .389 & \\
\hline 14. I am good at getting my babies attention; & .445 & & .646 & \\
\hline 15. I am good at knowing what activities my baby does not enjoy; & & & .687 & \\
\hline 16. I am good in keeping my baby occupied. & & & .664 & .392 \\
\hline 17. I am good at feeding my baby; & & .649 & & \\
\hline 18. I am good at changing my baby; & .329 & .804 & & \\
\hline 19. I am good at bathing my baby; & .330 & .728 & & .336 \\
\hline 20. I can show affection to my baby & & .759 & .438 & \\
\hline
\end{tabular}

Note: Extraction method: Principal Component Analysis. Rotation Method: Varimax with Kaiser Normalization. Rotation converged in 8 iterations.

number of painful procedures experienced by the baby, number of pregnancies, abortions and dead children of the mother, marital status and maternal education.

The One-Way ANOVA indicated that the total score was affected only by the variable fetal distress $[F(1,2)=3,159, p=.048]$. Maternal responses to item $1 \mathrm{I}$ believe I can tell when my baby is tired and needs to sleep were influenced by fetal distress $[F(1,2)=4,026, p=.022]$, number of prenatal visits $[F(1,71)=2,448, p=.010]$ and childbirth complications $[F(1,85)=4,347, p=.040]$. To Item 2 I believe that I have control over my baby were significant the effect of the variables gestational age $[F(1,11)=2,073, p=.039]$, Apgar $1[F(1,8)=2,585 \mathrm{p}=.016]$, Apgar $5[F(1,4)=3,715, p=.009]$, fetal distress $[F(1,2)=3,234, p=.007]$, number of previous pregnancies $[F(1,85)=2,171, p=.046]$ and childbirth complications $[F(1,85)=9,195$, $\mathrm{p}=.003$ ]. Item $3 \mathrm{I}$ can tell when my baby is sick the level of maternal education was significant $[F(1,86)=3,228, p=.007]$, birth complications $[F(1,85)=6,767, p=.011]$, number of previous pregnancies $[F(1,85)=2,942, p=.009]$. For item 4 I can read my baby's cues were significant the variables Apgar $5[F(1,4)=2,654, p=.037]$, number of previous pregnancies $[F(1,85)=2,230$, $\mathrm{p}=.040]$ and fetal distress $[\mathrm{F}(1,2)=3,444$, $\mathrm{p}=.037]$. The variable birth complications was significant for item 5I can make my baby happy $([F(1,85)=3,908, p=.051]$, for item $9 \mathrm{I}$ am good at soothing my baby when he/she becomes upset $[F(1,85)=4,310, p=.041]$ and for item 12 I am good at calming my baby when he/she becomes more restless $[F(1,85)=4,205$, $\mathrm{p}=.043]$. Smoking affected items $12[\mathrm{~F}(1,76)=$ $=3,514, \mathrm{p}=.065]$ and $13 \mathrm{I}$ am good at understanding what my baby wants $[F(1,76)=$ $=4,973, p=.029]$. Civil state was significant for the item $17 \mathrm{I}$ am good at feeding my baby $[F(1,86)=2,663, p=.053]$. Factor Reading
Behavior was affected by variable Apgar $5[F(1,4)$ $=2,339 p=.014]$, fetal distress $[F(1,2)=3,159$, $\mathrm{p}=.007]$ and the number of previous pregnancies $[F(1,85)=2,420, p=.027]$. The variable number of abortions did not reach statistical significance in the overall analysis, but in the post-hoc analysis (Bonferoni test for equal variance assumed) it was observed that for mothers who have had two or more abortions, abortion variable reached significant effect $(p=.000)$ on items $1,4,5,7,8$, $11,13,18,19$ and 20 . Variables mode of delivery, maternal age, number of painful procedures, age baby in days and deceased children had no statistical significance on the items or the scale factors.

Investigating whether the group factor exerted effect on maternal responses, two-way ANOVA analysis showed that the factor group itself has influence only on the item $1(4,974 *)$. Among the covariates that reached significance $(* \mathrm{p}<.05$; $* * \mathrm{p}<.001)$ on the items and factors of scale with the group as a factor are Apgar 1 on item 7 I believe that my baby and I have a good interaction with each other $(4,569 * *)$; Fetal distress on Reading behavior factor $(8,502 * *)$, item $7(8,502 * *)$, item $12 \mathrm{I}$ am good at calming my baby when he/she becomes more restless $(4,920 *)$, item $15 \mathrm{I}$ am good at knowing what activities my baby does not enjoy $(7,816 * *)$ and item $16 \mathrm{I}$ am good in keeping my baby occupied $\left(4,444^{*}\right)$; Childbirth complications on item $1(6,085 *)$ and item $2(6,665 *)$; number of the pre-natal consultations on item 1 $(6,388 *)$; number of previous pregnancies on items $3(7,561 * *), 4(8,165 * *)$ and item $19 \mathrm{I}$ am good at bathing my baby $(5,744 *)$; and number of abortions on item $4(6,016 *)$.

\section{DISCUSSION}

In this article we propose the validation of an instrument to measure the perception of maternal 
parenting self-efficacy in a sample of Brazilian population. Results provided support for reliability and validity of the instrument and its use with mothers of term infants and premature newborns in the neonatal period $^{13-14}$. The construct validity was assessed using EFA rather than confirmatory factor analysis. The PAEPM tool has 20 items grouped into four subscales representing different sub-domains of parenting that were detected by the EFA.

While limits of this study is the sample size used because according to Froman ${ }^{15}$ criteria the minimum number necessary for meaningful analysis is five participants per item ( $n=100$ in PAEPM scale) or 20 participants per factor $(n=$ 80) within scale. The largest number of participants can vary from 10 participants per item for several hundred. The sample of this study attended only the second criterion of 20 participants per factor. However, the consistency between the data found in this study and the original study results suggest replication of the study. Despite these limitations, the internal consistency coefficients of PAEPM were above the recommended approach ${ }^{13}$ and no higher alpha value was obtained if all items were excluded. However. internal consistency is only part of reliability testing.

Factor analyzes were conducted and revealed four conceptually unique subscales of parenting also replicating the original study. These findings suggest that this tool not only measures the construction of maternal self-efficacy, but also various dimensions of parental self-efficacy. The analysis of the matrix of the rotated components had different distribution possibilities of the items for each factor relative to the original structure of the scale. However, it was decided to keep the original structure of distribution of items that best fits the conceptual structure of the scale. Despite having the item 20 not reached the criteria used in Exploratory Factor Analysis it was decided to keep it in the final version validity of this scale according to their conceptual importance and for correlated items and components 3 and 4 of the matrix of rotated components.

The PAEPM scale has as its main objective the identification of mothers who have low levels of self-efficacy so that parenting can be used to focus the activities of the multidisciplinary team accompanying these mothers in the hospital. It can be used in contexts such as nurturing mother support programs because of the difficulty in breastfeeding some mothers may be associated with low self-efficacy percpetion ${ }^{16,17}$, for instance, the factors Taking Care or Situational Beliefs. Another application example is for the occupational therapy service where the scale could be used to evaluate the effectiveness of maternal interventions to nourish the baby sensory systems where the team would work on strengthening self-efficacy of maternal parenting. It can also be applicable in other situations where specific parental behaviors are being studied in an exploratory manner or as a support instrument to other studies such as the research of maternal mental states (e.g.: postpartum depression) ${ }^{18}$.
Clinical and sociodemographic variables emerged from analysis indicating strong relevance to negative impact on the concept of self-efficacy being the occurrence of fetal distress, maternity complications, gestational age, lower values of Apgar score, the greater number of abortions, the lowest level of education and maternal smaller number of previous pregnancies. The data that multiparous mothers have significantly higher perception of self-efficacy replicates the original study suggesting that the previous experience of motherhood increases the success of belief in the care task with baby ${ }^{1-3}$.

Smoking and maternal marital status (no fixed partner) were also relevant to lower selfefficacy scores, but with less impact on the items. Variables such as type of delivery, maternal age, number of painful procedures that the baby has suffered, baby age in days of life and number deceased children did not reach values that indicate possible effect on maternal perception of selfefficacy.

Prematurity as a factor when compared to the birth of term infants in general had no effect on the perception of maternal self-efficacy allowing consolidate the use of the scale for mothers of premature babies or full-term infants with similar characteristics. However, the results of some variables investigated in this study suggest caution when the application in mothers of prematurely born babies. These include Apgar score 1 minute that could have an effect on the quality of mother-child relationship (I believe my baby and I have a good relationship); the fact that the baby have experienced fetal distress that may decrease the scale scores on the factor Reading Behavior, the mother's ability to calm the baby (I'm good at calming my baby when he / she gets impatient) and maternal ability to stimulate and distract the baby (I'm good to know what activities my baby does not like and I know well how to keep my baby distracted). Other variables associated with prematurity as occurrence of birth complications, fewer prenatal visits and more abortions also exerted influence on some items and it is suggested that mothers of babies born prematurely and who have this combination of risk factors for the perception of self-efficacy are specially monitored by the hospital staff.

The capacity of the PMP SE tool to discriminate among mothers who were high or low on self-efficacy suggests that it may be useful to provide health professionals with important information about the screening of maternal parenting during the neonatal period. It is an especially dedicated instrument for the team of neonatal units advocating humanized models and empowerment of mothers as caregivers agents and allows teams to evaluate parenting skills in a more precise way ${ }^{19}$. The PAEPM scale is a tool to be also used in programs to support parenting during pregnancy and postpartum in the construction of maternal self-efficacy as an instrument of self knowledge $\mathrm{e}^{20}$. Specifically, it provides information that can be used to strengthen those with parental responsibility to make choices that will enhance their 
ability to care for their newborn babies as members of their families ${ }^{21-23}$. These programs, from the results obtained in the application of the scale, can support health professionals to nurture beliefs of mothers in specific activities or parental subdomains where the score was particularly low ${ }^{18}$.

Although estimates of reliability and validity of PAEPM instrument was demonstrated in this study, we recommend that future studies should be conducted through an analytical approach to confirmation factor and a larger sample of at least 200 participants to avoid possible conceptual confusion factors. Although there are conceptual differences between self-efficacy and self-care, these two constructs can be related and deserve further investigation in the context of neonatal unit ${ }^{24}$.

The PAEPM scale offers a methodology specially built to help the neonatal team on the

\section{REFERENCES}

1. Bandura A. Self-efficacy: toward a unifying theory of behavioural change. Psychol Rev. 1977; 84(2):191-215. DOI: http://dx.doi.org/ $10.1037 / 0033$

2. Bandura A. (1997) Self-Efficacy: The exercise of control. New York: Freeman ;1997.

3. Bandura A. Social cognitive theory: An agentic perspective. Ann Rev Psychol. 2001;52: 1-26. DOI: http://dx.doi.org/10.1146/annurev. psych.52.1.1

4. Flammer A. Self-Efficay. In: Smelser NJ, Baltes PB. International Encyclopedia of the Social \& Behavioral Sciences. Oxford, UK: Elsevier Science. 2004; p.13812-13815.

5. Coleman PK, Karraker KH. Self-Efficacy and Parenting Quality: Findings and Future Applications. Developmental Review. 1998;18(1):47-85. DOI: http://dx.doi.org/ 10.1006/drev.1997.0448

6. Salone $A H$, Kaunonen AM, Astedt-Kurki $P$, Jarvenpaa. AL, Isoaho H, Tarkka MT. Parenting self-efficacy after childbirth. J Adv Nurs. 2009;65(11):2324-36. DOI: http://dx.doi.org/ 10.1111/j.1365-2648.2009.05113.x

7. Figueira P, Corrêa H, Malloy-Diniz L, RomanoSilva MA. Escala de Depressão Pós-natal de Edimburgo para triagem no sistema público de saúde. Rev Saúde Pública. 2009;43(supl 1): 79-84. DOI: http://dx.doi.org/10.1590/S003489102009000800012

8. Motta MG, Lucion AB, Manfro GG. Efeitos da depressão materna no desenvolvimento neurobiológico e psicológico da criança. Rev Psiquiatr Rio Gd Sul. 2005; 27(2):165-76. DOI: http://dx.doi.org/10.1590/S0101-81082 005000200007

9. Schwengber DDS, Piccinini CA. O impacto da depressão pós-parto para a interação mãebebê. Estud Psicol. 2003;8(3):403-11. DOI: http://dx.doi.org/10.1590/S1413-294X200 3000300007

10. Moraes IG, Pinheiro RT, Silva RA, Horta BL, Sousa PL, Faria AD. Prevalência da depressão pós-parto e fatores associados. Rev de Saúde Pública. 2006;40(1)65-70. DOI: http:// screening parenting skills of mothers. She has clear, understandable and relevant items related to the operating area to be explored and identified through content validity. This test takes only 10 minutes to complete, making it easy to use in clinical settings. The original study recommended that the total score PMP SE tool should be used as a general indicator of level of self-efficacy, but the sub-scales should also be used to understand what support is needed by each individual.

This tool can provide health professionals with a reliable method of identification of mothers of premature babies and full-term infants in hospital situation that are in need of more support. Selfefficacy can therefore be a key mechanism to guide the interactions between the mother and her newborn baby and can be a powerful instrument of support to be used in humanized hospitals.

dx.doi.org/10.1590/S0034-891020060001 00011

11. Ruschi GEC, Sun SY, Mattar R, Chambô Filho A, Zandonade E, Lima VJ. Aspectos epidemiológicos da depressão pós-parto em amostra brasileira. Rev Psiquiatr Rio Gd Sul. 2009;29(3):274-80. DOI: http://dx.doi.org/ 10.1590/S0101-81082007000300006

12. Barnes CR, Adamson-Macedo EN. Perceived maternal parenting self-efficacy (PMP S-E) tool: development and validation with mothers of hospitalized preterm neonates. J Adv Nurs. 2007;60(5):550-60. http://dx.doi.org/ 10.1111/j.1365-2648.2007.04445.x

13. Nunnally JC, Bernstein IH. Psychometric theory. 3rd edn. New York: McGaw-Hill; 1994.

14. Bland JM, Altman DG. Statistics notes: Cronbach's alpha. Br Med J. 1997;314:572. DOI: http://dx.doi.org/10.1136/bmj.314. 7080.572

15. Froman RD. Elements to consider in planning the use of factor analysis. South Online J Nurs Res. 2001;5(2):1-22.

16. Loke AY, Chan LK. Maternal breastfeeding selfefficacy and the breastfeeding behaviors of newborns in the practice of exclusive breastfeeding. J Obstet Gynecol Neonatal Nurs. 2013;42(6):672-84. DOI: http:// dx.doi.org/10.1111/1552-6909.12250

17. Kucukoglu S, Celebioglu A. Effect of naturalfeeding education on successful exclusive breast-feeding and breast-feeding self-efficacy of low-birth-weight infants. Iran J Pediatr. 2014; 24(1): 49-56.

18. Benzies K M, Magill-Evans JE, Hayden KA, Ballantyne $M$. Key components of early intervention programs for preterm infants and their parents: a systematic review and metaanalysis. BMC Pregnancy Child. 2013;13(Suppl 1): s10. DOI: http://dx.doi.org/10.1186/14712393-13-S1-S10

19. Orem D. Nursing: concepts of practice. 6 th edn. London: Mosby; 2001.

20. Fulton JM, Mastergeorge AM, Steele JS, Hansen RL. Maternal perceptions of the infant: relationship to maternal self-efficacy during the first six weeks' postpartum. Infant Ment Health 
J. 2012;33(4): 329-38. DOI: http://dx.doi. org/10.1002/imhj.21323

21. Price C. Family centred care for the neonate the view from Wolverhampton. Neuro Endocrinol Lett. 2004;25(suppl 1):87-93.

22. Troutman B, Moran TE, Arndt S, Johnson RF, Chmielewski M. Development of parenting selfefficacy in mothers of infants with high negative emotionality. Infant Ment Health J. 2012; 33(1): 45-54. DOI: http://dx.doi.org/10.1002/ imhj. 20332
23. Swanson V, Nicol H, McInnes R, Cheyne $H$, Mactier $\mathrm{H}$, Callander E. Developing maternal self-efficacy for feeding preterm babies in the neonatal unit. Qual Health Res. 2009;22(10): 1369-82. DOI: http://dx.doi.org/10.1177/ 1049732312451872

24. Callaghan DM. Health-promoting self-care behaviors, self- care self-efficacy, and self-care agency. Nurs Sci Q. 2003;16(3):247-54. DOI: http://dx.doi.org/10.1177/08943184,0301 6003016

\section{Resumo}

Objetivo: esta pesquisa se propôs a avaliar o comportamento de autoeficácia materna em mães e gestantes hospitalizadas e validar um instrumento de medida deste para este conceito elaborado e validado na Inglaterra por Barnes e Adamson-Macedo, em 2007. A autoeficáciacorresponde a crenças que uma pessoa possui de que ela é capaz de produzir os resultados que deseja alcançar. As crenças de autoeficáciaque os pais têm sobre o bebê surgem como um poderoso preditor para práticas parentais positivas. Método: estudo exploratório observacional de corte de conveniência composta por mães de 87 bebês recém-nascidos, sendo 26 bebês nascidos prematuros e 61 bebês nascidos a termo.A escala de Percepção de Autoeficáciade Parentalidade Materna (PAEPM), que é composta por 20 itens que representam quatro sub-escalas, foi testada para a confiabilidade e validade. Resultados: a consistência interna da escala PAEPM alcançou o valor de .86, As estimativas de consistência interna e confiabilidade para cada uma das sub-escalas também atingiu valores aceitáveis. Análise Fatorial Exploratória (AFE) confirmou a validade do constructo e osescores de autoeficáciaforam normalmente distribuídos para ambos os subgrupos e amostra total. Conclusões: a escala PAEPM mostrou ser uma ferramenta de fácil aplicação e psicometricamente robusta, confiável e válida para uso com mães de recém-nascidos tanto prematuros quanto a termo hospitalizados com quadro clinico estável. É um método confiável de identificação de mães de bebês hospitalizados que precisam de mais apoio das equipes hospitalares.

Palavras-chave: auto-eficácia, cuidado neonatal, parentalidade, validação, psicologia da saúde. 